\title{
Water tubing injury: An overlooked boating injury statistic
}

A 23-year-old female sustained a large avulsion injury to the groin while water tubing on a local waterway. The laceration began at the mons pubis, extended along the labia majora with involvement of the external anal sphincter. The pubic bone and the pectineus muscle were exposed. Six weeks after surgery, she had resumed full activity without sequlae. Lack of data and the potential for significant injury caused by water tubing as described in this case report are a real concern. Water tubing injury should be classified as a primary accident type and analyzed by the U.S. Coast Guard.

Key words: Avulsion, boating injury, straddle injury, water tubing

Jonathan D. Baum, Andrew L. Atkinson

Department of Obstetrics and Gynecology, Jersey Shore University Medical Center, Neptune, NJ

Address for the Correspondence:

Dr. Andrew L. Atkinson, Jersey Shore University Medical Center, 1945 State Route 33, Neptune, NJ 07754.

E-mail: A. AtkinsonMD@Gmail.com

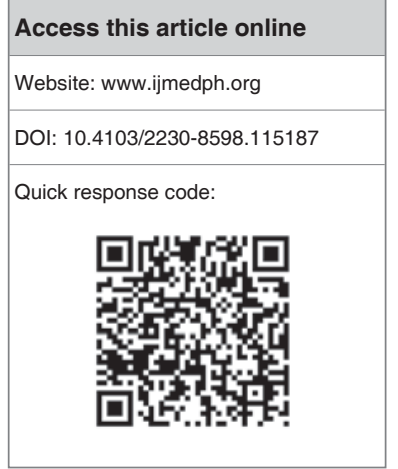

\section{INTRODUCTION}

Recreational boating injuries are tracked and analyzed by the United States Coast Guard under Title 46, United States Code. The Prevention Policy Directorate Office of Auxiliary and Boating Safety, Boating Safety Division has Recreational Boating Safety Program responsibility. ${ }^{[1]}$ While water skier mishap is in the top five primary accident types reported for recreational boating, the actual rates of water tubing injury are not documented as a separate category. A study conducted by Heinsimer et al., (from 1991 through 2009) estimated that 69,471 injuries from 1991-2009 were treated in US emergency departments for water tubing-related injuries. The annual number of cases increased $250 \%$ over the 19-year study period. ${ }^{[2]}$ Water tubing is similar to water skiing in that the skier is pulled behind a motorboat. The person water tubing has little control over their ride and may be subject to injury via collision with floating obstacles and/or force of wave or wake. ${ }^{[1,3]}$ In 1998, Parmer et al. described a case series of pediatric injuries due to water tubing and suggested that this water sport was increasing in popularity. All injuries in their case series were orthopedic in nature. ${ }^{[4]}$ In 2010 , only $6.5 \%$ of primary recreational boating injuries were classified as laceration injuries to the trunk. ${ }^{[1]}$ This is the first documented case of a groin laceration due to water tubing. For the purpose of this report, we assume that water tubing is a subset of skier mishap and that groin laceration is a subset of injury to the trunk.

\section{CASE REPORT}

A 23-year-old nulligravid African American female presented to the emergency room complaining of left hip pain and bleeding from an unspecified location. She stated that she was water tubing behind a boat when she lost control; fell forward onto the tow rope and into the water. During her swim back to the boat, she noticed a trail of blood in the water and began to feel pain in her groin.

The patient was an out of state visitor vacationing with her family at the Jersey Shore. Her body mass index (BMI) was 34. She was single and sexually active. There was no other significant past medical, surgical, gynecologic, family, or social history. Despite intravenous narcotics, the patient could not tolerate physical examination. Pre-operative hemoglobin was $9.1 \mathrm{mg} / \mathrm{dL}$. X-ray of the left hip was negative for fracture. A single dose of broad-spectrum antibiotics was administered. Brisk bleeding was noted once the patient's legs were positioned in the operating room. Bladder catheterization showed clear urine. Examination under anesthesia showed a $5 \times 5 \mathrm{~cm}$ avulsion injury involving the mons pubis with exposure of the pubic bone as well the origin and proximal belly of the left pectineus muscle [Figure 1]. 


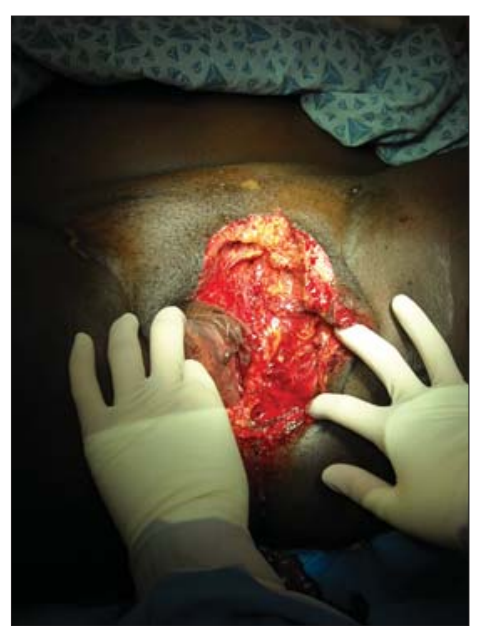

Figure 1: Avulsion Injury measuring $5 \times 5$ centimeters. Laceration traveling down the left labia majora with extension to the external anal sphincter

The avulsion began on the right side of the mons pubis and crossed the midline at the anterior labial commissure then descended along the left labia majora as a laceration $12 \mathrm{~cm}$ long and $1 \mathrm{~cm}$ deep. The laceration extended to the external anal sphincter. A $3^{\text {rd }}$ degree laceration of the sphincter was noted. Speculum examination showed an intact vagina without signs of injury. The urethral meatus was intact.

Repair of the injury began with lavage and debridement of devitalized tissue. Hemostasis was achieved via suture ligation, cautery, and applied pressure. The avulsed tissue was repaired in layers beginning with the underlying fascia followed by the subcutaneous adipose layer using synthetic absorbable suture. The vulvar laceration was also repaired in layers. The disrupted capsule of the external anal sphincter was repaired with interrupted synthetic absorbable suture. The skin was closed with interrupted absorbable sutures placed 5-6 mm apart along the body of the laceration [Figure 2]. Rectal exam showed normal tone after repair. Operating time was 90 minutes. She was discharged home in stable condition. The post-operative course was uncomplicated. The sutures were removed on post-operative day number 10 due to patient discomfort. She returned to her home state. She was contacted by phone six weeks later and had already resumed full activity without sequelae.

\section{CONCLUSION}

We present an atypical avulsion injury to the groin extending from the superior aspect of the mons pubis to the external anal sphincter. The injury in this case was caused by frictional force applied across the external soft tissues of the groin. The patient was being towed at high speed in choppy water when her tube caught the back side of a wave

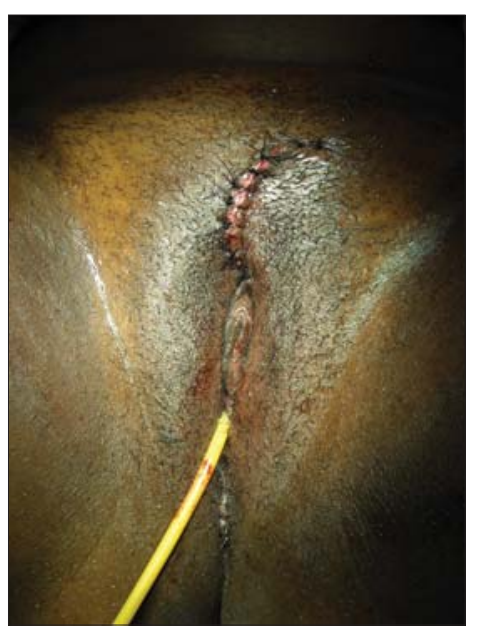

Figure 2: Post-operative repair with urinary catheter in place

causing a sudden deceleration. The tension along the tow rope increased as she fell forward straddling the rope. The rope and tube were then pulled between her legs causing the avulsion and lacerations as described.

Water tubing is growing in popularity and is similar to water skiing in that the person water tubing is pulled behind a motorboat. The participant in this case was indirectly injured via force of wave that led to direct injury by the tow rope.

We contacted the U.S. Coast Guard headquarters located in Washington D.C. to discuss this case report and our recommendation. ${ }^{[5]}$ They acknowledged that water tubing injuries have become an increasing problem in recreational boating across the United States and warrant consideration for classification as their own primary accident type.

\section{REFERENCES}

1. U.S. Coast Guard. Recreational Boating Statistics 2010. Washington: Government Printing Office; 2011.

2. Heinsimer KR, Nelson NG, Roberts KJ, McKenzie L. Water Tubing-Related Injuries Treated in US Emergency Departments, 1991-2009. J Phys Act Health 2012;29 [In Press].

3. Vukich CL. Carp Versus Cranium: A Fishy Story. J Trauma Nurs 2007;14:88-92.

4. Parmer P, Letts M, Jarvis J. Injuries Caused by Water Tubing. J Pediatr Orthop 1998;18:49-53.

5. Commandant United States Coast Guard. $21002^{\text {nd }}$ Street, S.W. Stop 7581, Washington, DC: Jan. 19, 2013.

How to cite this article: Baum JD, Atkinson AL. Water tubing injury: An overlooked boating injury statistic. Int J Med Public Health 2013;3:117-8.

Source of Support: Nil, Conflict of Interest: None declared. 